\title{
Estrogen-regulated miRNA-27b is altered by bisphenol $A$ in human endometrial stromal cells
}

\author{
Beverly G Reed, Samir N Babayev, Lucy X Chen, Bruce R Carr, R Ann Word and \\ Patricia T Jimenez \\ Division of Reproductive Endocrinology and Infertility, Department of Obstetrics and Gynecology, Green Center for \\ Reproductive Biological Sciences, University of Texas Southwestern Medical Center, Dallas, Texas, USA \\ Correspondence should be addressed to P T Jimenez; Email: jimenezp@wustl.edu
}

\begin{abstract}
MicroRNAs (miRs) are small molecules important for regulation of transcription and translation. The objective was to identify hormonally regulated miRs in human endometrial stromal cells and to determine the impact of the endocrine disruptor, bisphenol $A$ (BPA), on those miRs. miR microarray analysis and multiple confirmatory cell preparations treated with 17 $\beta$-estradiol (E2) and BPA altered miR-27b, let-7c, let-7e and miR-181b. Further, decidualization downregulated miR-27b. VEGFB and VEGFC were validated as targets of miR-27b. Identification of miR-27b target genes suggests that BPA and E2 downregulate miR-27b thereby leading to upregulation of genes important for vascularization and angiogenesis of the endometrium during the menstrual cycle and decidualization.
\end{abstract}

Reproduction (2018) 156 559-567

\section{Introduction}

Endometrial development is the result of a carefully coordinated set of events largely controlled by steroid hormones. 17 $\beta$-estradiol (E2) mediates growth and vascularization of the endometrium. After ovulation, progesterone (P4) induces endometrial differentiation and receptivity. If implantation does not occur, progesterone levels fall resulting in endometrial shedding and menstruation. Implantation is a complex, precisely timed event, and it is an important limiting step in reproduction for many women. Implantation failures may be related to immunologic factors, endocrine or hormonal disruptions, lack of endometrial receptivity, anatomic defects (leiomyomas, intrauterine adhesions) or embryo factors (Bechi et al. 2010, Makker \& Goel 2013, Qiong et al. 2017, Zhang et al. 2017). However, there are many cases in which a cause for implantation failure cannot be found. Whereas assisted reproductive technologies (ARTs) may overcome some cases of unexplained infertility, many women continue to have implantation failures despite transfer of good-quality euploid embryos in multiple sequential cycles (recurrent implantation failure) emphasizing that a critical aspect of achieving pregnancy in both natural and ART cycles is successful implantation. The mechanisms that regulate endometrial development and embryo implantation, and thus, implantation failure, are not clearly defined. It is hypothesized that steroid hormone-induced differentiation of endometrial cells may be impaired in not only implantation failure, but also in a number of gynecologic disorders including endometriosis, adenomyosis, abnormal uterine bleeding and endometrial adenocarcinoma.

As a hormone-responsive tissue, the endometrium is susceptible to endocrine-disrupting chemicals (EDCs). EDCs are exogenous chemicals that interfere with hormone action (Diamanti-Kandarakis et al. 2009). Common EDCs include bisphenol A (BPA), diethylstilbestrol (DES), dichlorodiphenyltrichloroethane (DDT) and polychlorinated biphenyl (PCB). Recently, there has been increased interest in the impact of EDCs on many aspects of human development. Exposure to EDCs may affect reproduction and increase the risk of precocious puberty and infertility (Diamanti-Kandarakis et al. 2009). A better understanding of how EDCs may lead to pathologic conditions is needed.

BPA, a chemical widely used in products such as plastics, thermal paper and dental sealants, has weak estrogenic activity (Krishnan et al. 1993, Gore 2007). Most people in industrial countries are exposed to low levels of BPA through oral ingestion or transdermal absorption (Calafat et al. 2008, Liao et al. 2012, Hormann et al. 2014). Animal studies have shown that low levels of BPA cause changes in behavior, brain development, the prostate gland, the mammary gland and the age at which the females attain maturity (Berger et al. 2007, Itoh et al. 2012a, Machtinger \& Orvieto 2014). Human data are limited to epidemiologic studies. Nonetheless, BPA exposure has been linked to an increased risk for many 
diseases including diabetes and cardiovascular disease (Rancière et al. 2015, Provvisiero et al. 2016). It may also play an important role in tissue remodeling (Dairkee et al. 2013, Hwang et al. 2013, Dong et al. 2014, Chen et al. 2015, Nakano et al. 2016). In regard to fertility, BPA may affect reproduction in multiple ways including uterine/endometrial factors, ovarian factors, semen parameters and implantation (Sugiura-Ogasawara et al. 2005, Meeker et al. 2010, Peretz et al. 2014, Barbonetti et al. 2016, Forte et al. 2016, Ganesan \& Keating 2016, Ziv-Gal \& Flaws 2016, Mansur et al. 2017). Souter et al. observed an inverse relationship between urinary BPA concentration and the ovarian antral follicle count (a commonly used marker for ovarian reserve; Souter et al. 2013). In addition, women with the highest quartiles of urinary BPA concentrations had increased odds of implantation failure during in vitro fertilization treatment (IVF) (Ehrlich et al. 2012). Others have sought to understand the effect of BPA on endometrial stromal cells (Aghajanova \& Giudice 2011, Forte et al. 2016). Because of its weak estrogenic effects, BPA may increase endometrial stromal cell proliferation. However, BPA resulted in unchanged or decreased proliferation of endometrial stromal cells (Aghajanova \& Giudice 2011, Forte et al. 2016). Importantly, BPA exposure also may affect stromal cell differentiation and decidualization (Forte et al. 2016). Because endometrial stromal cell proliferation, differentiation and decidualization are critical for implantation, BPA exposure may negatively impact fertility.

MicroRNAs (miRs) are small, non-coding RNAs that bind to and functionally silence or degrade target mRNAs. There is a large and growing body of evidence demonstrating that miRs are involved in both the normal physiologic state and in pathologic gynecologic diseases such as endometriosis, leiomyomata and endometrial cancer (Kuokkanen et al. 2010, Snowdon et al. 2011, Rekker et al. 2013, Marsh et al. 2016, Nothnick et al. 2016, Wilczynski et al. 2016, Chen et al. 2017a, Logan et al. 2017). Therefore, our objectives were to identify hormonally regulated miRs in endometrial stromal cells and to investigate the effects of BPA on selected miRs.

\section{Materials and methods}

\section{Primary human endometrial stromal cell preparation}

Studies with human tissue samples were approved by University of Texas Southwestern Medical Center/Parkland Medical Health System IRB and informed consent was obtained from each woman prior to surgery. Endometrium was scraped from the uterus of reproductive aged females (18-45 years) undergoing hysterectomy for benign conditions. Patients who used exogenous hormone within the 30 days prior to surgery were excluded. Histologically confirmed proliferative phase endometrium was used for these studies. Samples were excluded if they contained any endometrial pathology such as endometrial polyps or endometrial hyperplasia.
Tissue digestion was performed for $60 \mathrm{~min}$ at $37^{\circ} \mathrm{C}$ with a solution of HBBS, collagenase type I $(1 \mathrm{mg} / \mathrm{mL}$, Sigma) and DNase I $(0.1 \mathrm{mg} / \mathrm{mL}$, Sigma). The cells were passed through a $70 \mu \mathrm{m}$ filter to separate the epithelial glandular cells from the stromal cells. The epithelial glandular cells were discarded. The human endometrial stromal cells (HESCs) were placed in growth media (phenol-free DMEM:F12, Hepes $15 \mathrm{mM}, 10 \%$ fetal bovine serum, 1\% antibiotic/antimycotic) and cultured until $70-90 \%$ confluent. Cells were not used beyond the third passage.

\section{microRNA microarray analysis}

HESCs were serum-starved for $24 \mathrm{~h}$ and then treated with vehicle (V), 3 nM E2, $100 n M$ P4 or a combination of 3 nM E2+ $100 \mathrm{nM}$ P4 for $16 \mathrm{~h}$. E2 and P4 concentrations were chosen because (i) prior studies show endometrial stromal cells are responsive at these concentrations (Casey et al. 1991, Itoh et al. 2012b) and (ii) these concentrations are comparable to physiologic levels (Lenton et al. 1982, Kettel et al. 1991). miRNA microarray was performed by LC Sciences with two micrograms of total RNA for each sample and run in triplicate as previously described (Renthal et al. 2010, Jimenez et al. 2016). In brief, RNA was fractionated; small RNAs were extended with poly (A) polymerase and labeled. Paraflo microfluidic chip with 2565 mature human miRNAs was used for hybridization (miRBase Sequence Database, version 6). Multiple redundant regions were included in which each region consisted of miRNA probes that detect miRNA transcripts listed in Sanger miRBase Release 21 (http://www.mirbase.org/). Multiple control probes were included on each chip. Signal intensities increased from 1 to 65,535 . During data processing, signal values that deviated $>50 \%$ of average values of repeating spots were discarded. Signals with $P$ values $<0.01$ compared with background were considered detectable. After subtraction of background, data were $\log _{2}$ transformed. Datasets are available in the Gene Expression Omnibus (GEO) and Supplementary Tables 1, 2 and 3 (see section on supplementary data given at the end of this article). Biological processes enriched in estrogen-treated cells were determined using gene ontology annotation clustering using DAVID Bioinformatics Resources with $P$ values $<0.02$ as the cut-off. The miRs that were highly expressed and found to be statistically significantly different from the vehicle or other treatment groups with a $P$ value of $<0.05$ were chosen for further analysis.

\section{Hormone studies}

HESCs were plated in growth media until $80 \%$ confluency. The cells were serum starved for $24 \mathrm{~h}$ prior to treatment with vehicle, $3 \mathrm{nM}$ E2 or BPA at various concentrations $(30 \mathrm{nM}$, $300 \mathrm{nM}$ or $3000 \mathrm{nM})$. Cells were harvested at $4 \mathrm{~h}, 8 \mathrm{~h}, 16 \mathrm{~h}$ or $24 \mathrm{~h}$ for RNA analysis.

\section{Quantitative reverse transcription PCR of miRs}

Total RNA was reverse transcribed using the TaqMan MicroRNA Reverse Transcription Kit (Applied Biosystems) or the TaqMan Advanced miRNA cDNA Synthesis Kit (Applied Biosystems). 
qPCR was performed with miR-specific TaqMan MicroRNA Assays or Taqman Advanced miRNA Assays and TaqMan Gene Expression Master Mix. The RT-qPCR was run on a 7500 RealTime PCR System (Applied Biosystems, Foster City, CA) and normalized to U6 snRNA, miR-26a, miR-221 and/or miR-191 with the $\delta-\delta$ cycle threshold method.

\section{RT-qPCR of mRNA expression}

Reverse transcription was performed using iScript Reverse Transcription Supermix for RT-qPCR (Bio-Rad Laboratories). Primers were used with SYBR Green Master Mix to determine gene expression on a 7500 Real-Time PCR System (Applied Biosystems). Relative mRNA expression was calculated by the $\delta$ - $\delta$ cycle threshold method.

\section{Transfection of HESCs}

HESCs were cultured to $70 \%$ confluency. Experiments were conducted to optimize and validate transfection efficiency. After serum deprivation for $24 \mathrm{~h}$, HESCs were transfected with the miR mimic positive control (25 pmol/well, mirVana miRNA Mimic miR-1 Positive Control) or the miR inhibitor positive control (25 pmol/well, mirVana miRNA Inhibitor let-7c Positive Control) at three doses of Lipofectamine RNAiMAX $(29 \mu \mathrm{L} / \mathrm{mL}$, $60 \mu \mathrm{L} / \mathrm{mL}$ or $128 \mu \mathrm{L} / \mathrm{mL}$ ) (Supplementary Fig. 1). Media were changed at $24 \mathrm{~h}$ and cells harvested $48 \mathrm{~h}$ after transfection for RNA analysis. Additional transfection experiments with miR$27 \mathrm{~b}$ mimic and miR-27b inhibitor were performed with $29 \mu \mathrm{L} /$ $\mathrm{mL}$ Lipofectamine RNAiMAX for $48 \mathrm{~h}$.

\section{In vitro decidualization}

HESCs were plated at $3 \times 10^{5}$ cells/well in six-well plates in DMEM:F12 phenol red-free media and allowed to adhere to the plates. At $24 \mathrm{~h}$, the media was changed to include $0.1 \% \mathrm{EtOH}$ (vehicle) or $1 \mu \mathrm{M}$ medroxyprogesterone acetate and $0.5 \mathrm{mM}$ dibutyryl cAMP (decidualization media). The treatment media were changed every third day until cell harvest after 8 days.

\section{VEGF-B ELISA}

HESCs were plated in six-well plates and grown to confluence in DMEM:F12 phenol red-free media with $10 \%$ charcoalstripped serum. Thereafter, cells were rinsed and treated with vehicle $(0.1 \% \mathrm{EtOH})$ or $\mathrm{E} 2(3.6 \mathrm{nM})$ in $1.0 \mathrm{~mL}$ of serum-free media in triplicate for 4 days. To ensure that $\mathrm{E} 2$ remained active, E2 or vehicle was added to the media every $24 \mathrm{~h}$. VEGF-B protein was quantified in the media using the human VEGFB ELISA Kit (LSBIO, catalog no. LS-F5203, Seattle, WA, USA) according to the manufacturer's instructions. Each experiment was calibrated with the standard amounts of known protein in blank media, and linear concentration-dependent curves were obtained. Each sample was measured in duplicate.

\section{Statistical analysis}

Analyses were performed with GraphPad Prism, version 6. Each experiment was performed in triplicate on multiple cell preps as noted in figure legends. Student's T-test, ANOVA with Tukey's or Dunn's post hoc analyses were used as appropriate to make comparisons among treatment groups or with controls. $P$ values $\leq 0.05$ were considered statistically significant. Statistical analysis of microarray data is described above.

\section{Results}

\section{Multiple miRs are differentially regulated by hormonal treatments}

To initiate discovery of potential hormonally regulated miRs in endometrial stromal cells, HESCs were treated with vehicle, $3 \mathrm{nM}$ E2, $100 \mathrm{nM}$ P4 or E2 $(3 \mathrm{nM})+\mathrm{P} 4$ (100 nM) for $16 \mathrm{~h}$ and microarray analysis was conducted. A heat map of selected differentially expressed microRNAs is shown in Supplementary Fig. 2A, and comprehensive lists of differentially expressed miRs with hormone treatment are provided in Supplementary Tables 1, 2 and 3.

\section{Reference microRNA validation}

To confirm the microarray findings, validation of reference microRNAs was required. Microarray analysis identified miRs with stable expression in HESCs (Supplementary Fig. 2B). NormFinder (https:// moma.dk/normfinder-software) indicated that the most stable miR across all treatment groups was miR-221-3p (Table 1). Four additional candidate reference microRNAs (miR-26a-5p, miR-186-5p, miR-191-5p and miR-361-5p) were selected based on stability in other reproductive tissues or per recommendations from Applied Biosystems (Shen et al. 2011). Expression of the miRs in HESCs was analyzed by RT-qPCR followed by NormFinder (Table 1). Hormonal treatment did not affect expression of these miRs. Because miR-26a-5p, miR-191-5p and miR-221-3p were the most highly expressed and stable in all experiments, these miRs were validated (Table 1) and used as reference miRs for TaqMan Advanced miR assays. Specifically, expression of the target miR was normalized to the mean of miR-26a-5p, miR-191-5p and miR-221-3p using the $\delta-\delta$ Ct method.

Table 1 NormFinder stability indexes in human endometrial stromal cells.

\begin{tabular}{lccc}
\hline \multicolumn{4}{c}{ Stability value } \\
\cline { 2 - 4 } miR & $\begin{array}{c}\text { Microarray primary } \\
\text { HESCs }\end{array}$ & $\begin{array}{c}\text { qPCR primary } \\
\text { HESCs }\end{array}$ & $\begin{array}{c}\text { qPCR cell line } \\
\text { T-HESCs }\end{array}$ \\
\hline $26 a-5 p$ & 0.224 & 0.002 & 0.005 \\
$186-5 p$ & N.D. & 0.006 & N.D. \\
$191-5 p$ & 0.160 & 0.002 & 0.007 \\
$221-3 p$ & 0.086 & 0.020 & 0.011 \\
$361-5 p$ & N.D. & 0.005 & 0.007 \\
\hline
\end{tabular}

HESCs, human endometrial stromal cells; N.D., not done. 

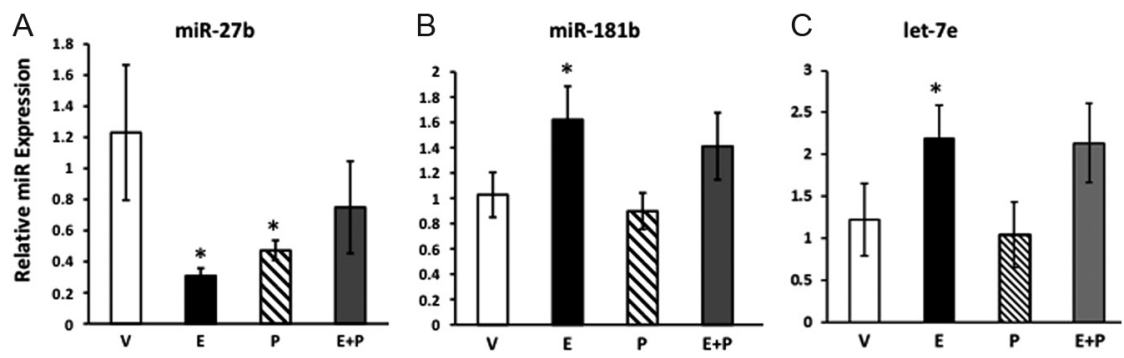

Figure 1 Effect of estrogen and progesterone on miR expression in HESCs. Cells were treated with vehicle $(\mathrm{V})$, estradiol $(\mathrm{E}, 3 \mathrm{nM})$, progesterone $(\mathrm{P}, 100 \mathrm{nM})$ or $\mathrm{E}+\mathrm{P}$ for $24 \mathrm{~h}$. Data represent mean \pm S.E.M. of representative experiment conducted in triplicate and replicated in an additional cell prep. ${ }^{*} P<0.05$ compared with control, ANOVA with Dunnett's post hoc analysis.

\section{miR-27b, miR-181b and let-7c are affected by E2 and $B P A$}

To confirm our microarray findings, we selected miRs that were highly expressed, highly conserved and significantly different from vehicle in hormone-treated cells (E2, P4 or both). These criteria, together with biological plausibility, led us to analyze miR-27b-3p, miR-181b-5p, miR-3613-3p, let-7c-5p, let-7e-5p and let-7f-5p. Because miR-3613 and let-7f were not consistently expressed in endometrial stromal cells, they were not analyzed in subsequent experiments. Whereas both E2 and P4 downregulated miR-27b, miR-181b and let-7e were upregulated by E2, but not P4 (Fig. 1). The results, therefore, were not completely congruous with microarray results in which progesterone upregulated let-7e. Thus, we focused the investigation on estrogenresponsive miRNAs and conducted pathway analysis for genes regulated by E2-responsive miRNAs. The top nine biological processes are listed in Table 2. Interestingly, the predominant biological process predicted to be greatly enriched by estrogen-regulated miRNAs was regulation of endothelial cell migration (18-21 fold, Table 2).

Serum concentrations of BPA in human subjects range from 1 to $10 \mathrm{ng} / \mathrm{mL}$ although higher concentrations may be found in other biological fluids such as amniotic fluid. Hence, our initial dose response with BPA was conducted from $30 \mathrm{nM}(6 \mathrm{ng} / \mathrm{mL})$ to $3 \mu \mathrm{M}$ for $24 \mathrm{~h}$. Progesterone receptor (PR) gene expression was used as a classic estrogen-responsive gene in HESCs. Thus, cells were treated with E2 (3nM), BPA (30-3000 nM) or E2 $(3 \mathrm{nM})+\mathrm{BPA}(3 \mu \mathrm{M})$ for $24 \mathrm{~h}$. Thereafter, RT-qPCR was performed to validate selected miRs and $P R$ as an index of estrogen responsiveness (Fig. 2). BPA, at concentrations of $300 \mathrm{nM}$, increased PR gene expression and downregulated miR-181b. miR-27b was not regulated by E2 or BPA at $24 \mathrm{~h}$. These experiments indicate that the cells are responsive to BPA and BPA does not appear to have additive effects with E2. Similar to other investigations in cell culture systems (Dairkee et al. 2013, Hwang et al. 2013, Dong et al. 2014, Chen et al. 2015, Nakano et al. 2016), further experiments were conducted with $3 \mu \mathrm{MBPA}$. The lack of BPA-induced regulation of miR-27b at $24 \mathrm{~h}$, although consistent with microarray data, led us to conduct temporal relationships between E2- and BPA-induced regulation of miR-27b, miR-181b, let-7c and let-7e (Fig. 3).

All experiments showed no change in any miR with vehicle alone as a function of time in culture (Fig. 3A, Ctl). $\mathrm{E} 2$, however, resulted in time-dependent regulation of four miRs, but the time course varied thereby explaining the lack of response of some miRs at $24 \mathrm{~h}$ (Fig. 3A). The time course of BPA-induced regulation of miR$27 \mathrm{~b},-181 \mathrm{~b}$, let-7c and let-7e was compared with that of E2 (Fig. 3A and B). Both E2 and BPA downregulated $\mathrm{miR}-27 \mathrm{~b}$ expression in the $8-16 \mathrm{~h}$ time frame. BPA also resulted in significant downregulation of miR-181b from 8 to $16 \mathrm{~h}$ with return to normal levels by $24 \mathrm{~h}$. Let-7c was downregulated by E2 and BPA, but the time course differed between E2 and BPA (Fig. 3). Let-7e was most significantly affected in the E2 treatment group at the 24-h time point. Taken together, these data indicate that E2 (in physiological concentrations) and BPA time dependently regulate expression of $\mathrm{miR}-27 \mathrm{~b}, \mathrm{miR}-181 \mathrm{~b}$ and let-7c. In addition, let-7e is affected by E2, but not BPA during this treatment timeframe.

Table 2 Enrichment analysis of predicted biological processes affected by estrogen-regulated microRNAs.

\begin{tabular}{lrrr}
\hline Biological process term & \multicolumn{1}{c}{$\%$} & $\boldsymbol{P}$ value & Fold enrichment \\
\hline GO:0045449 regulation of transcription & 25.17 & $6.40 \mathrm{E}-07$ & 1.75 \\
GO:0006350 transcription & 19.58 & $6.50 \mathrm{E}-05$ & 1.68 \\
GO:0051252 regulation of RNA metabolic process & 16.43 & $6.14 \mathrm{E}-04$ & 1.64 \\
GO:0010596 regulation of endothelial cell migration & 1.40 & $1.23 \mathrm{E}-03$ & 18.06 \\
GO:0006355 regulation of transcription, DNA-dependent & 15.38 & $2.34 \mathrm{E}-03$ & 1.57 \\
GO:0006357 regulation of transcription from RNA polymerase Il promoter & 7.69 & $5.34 \mathrm{E}-03$ & 7.03 \\
GO:0007242 intracellular signaling cascade & 11.19 & 1.91 \\
GO:0043537 regulation of blood vessel endothelial cell migration & 1.05 & $8.26 \mathrm{E}-03$ & 1.61 \\
GO:0008219 cell death & 7.34 & $9.67 \mathrm{E}-03$ & 21.07 \\
\hline
\end{tabular}

$\%$ represents involved genes/total genes. $P$ value represents EASE Score, a modified Fisher Exact $P$ value to measure the probability of Count/List total) is more than random compared with background list. 

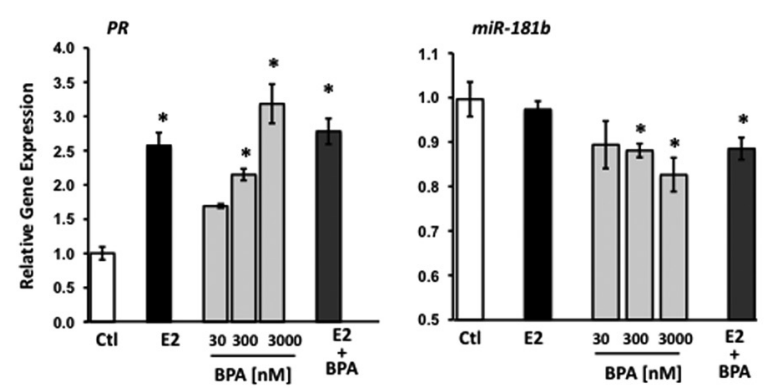

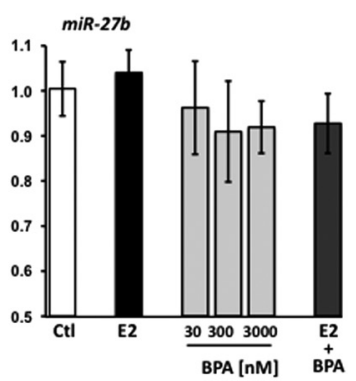

Figure 2 BPA dose-dependently regulates PR and miR-181b gene expression. HESCs were treated with vehicle $(\mathrm{Ctl}), \mathrm{E} 2(3 \mathrm{nM}), \mathrm{BPA}$ $(30-3000 \mathrm{nM})$ or E2 $3 \mathrm{nM}$ and BPA $3000 \mathrm{nM}$ for $24 \mathrm{~h}$. Data represent mean \pm S.E.M. of representative experiment conducted in triplicate and replicated in an additional cell prep. ${ }^{*} P<0.05$ compared with control, ANOVA with Dunnett's post hoc analysis.

\section{Potential targets of miR-27b: VEGFB and VEGFC}

Next, we sought to identify miR-27b targets and the potential physiological relevance of E2- and BPA-induced regulation of miR-27b. This particular miR was chosen because (i) the magnitude of suppression and time course of suppression at 8 and $16 \mathrm{~h}$ by E2 and BPA were similar and (ii) miR-27b has been shown to be important for other tissues that undergo significant remodeling and vascularization (Kang et al. 2013, Chen et al. 2017b). TargetScan (www.targetscan.org) was used to screen potential miR-27b targets. Several mRNA targets (estrogen receptor $\alpha, E R \alpha$; estrogen receptor $\beta, E R \beta$; progesterone receptor, $P G R$; Forkhead box O3, FOXO3; Forkhead box O1, FOXO1; insulin-like growth factor-binding protein 1, IGFBP1; vascular endothelial growth factors, VEGFA, VEGFB, VEGFC, VEGFD, and HomeoboxA10, HOXA10A) were analyzed in HESCs treated with or without BPA. Of these, most were not consistent with regulation by miR$27 \mathrm{~b}$ at the transcriptional level (not shown), or, in the case of VEGFD, were poorly expressed. VEGFB and VEGFC, but not VEGFA, demonstrated patterns compatible with potential miR-27b targets. To test if VEGFB was regulated by miR-27b in HESCs, cells were transfected with nontargeting, miR-27b mimic or miR-27b inhibitor oligomers. Consistent with our experiments demonstrating no effect of BPA, VEGFA was not regulated by miR-27b (Fig. 4A). $V E G F B$ gene expression, however, was decreased significantly by miR-27b mimic in four cell preps from different patients (Fig. 4A). Although gene expression was not increased by inhibitor alone, the inhibitor reversed miR-27b mimic-induced downregulation of VEGFB (Fig. 4B). Likewise, miR-27b mimic downregulated VEGFC significantly (Fig. 5A). Whereas miR-27b inhibitor upregulated, miR-27b mimic downregulated VEGFC 50\%, and the inhibitor reversed its downregulation (Fig. 5B).

To confirm that these targets were upregulated at the protein level, we analyzed VEGF-C and VEGF-B protein in control and E2-treated cells. The amount of VEGF-C protein was too low to detect reliably in stromal cell conditioned media despite concentrating the media five-fold. On the other hand, VEGF-B was readily detectable. The experiment was conducted after 4-day treatment to optimize the accumulation of the protein. Treatment of HESCs with E2 $(3.6 \mathrm{nM})$ for 4 days resulted in six-fold increases in the estrogen-responsive gene, PR-B (Fig. 6A). E2 treatment resulted in modest, but significant, increases in VEGF-B gene expression (Fig. 6A) and proportionate increases in VEGF-B accumulation in the media (Fig. 6B). Taken together, $V E G F B$ is a target of miR-27b in endometrial stromal cells. These findings are compatible with our pathway analysis of microarray data showing estrogen-induced enrichment of endothelial cell migration (Table 2).

\section{miR-27b expression is downregulated in decidualized cells}

To determine if miR-27b expression is altered during decidualization, HESCs were treated with dibutyryl

\section{A Estradiol}
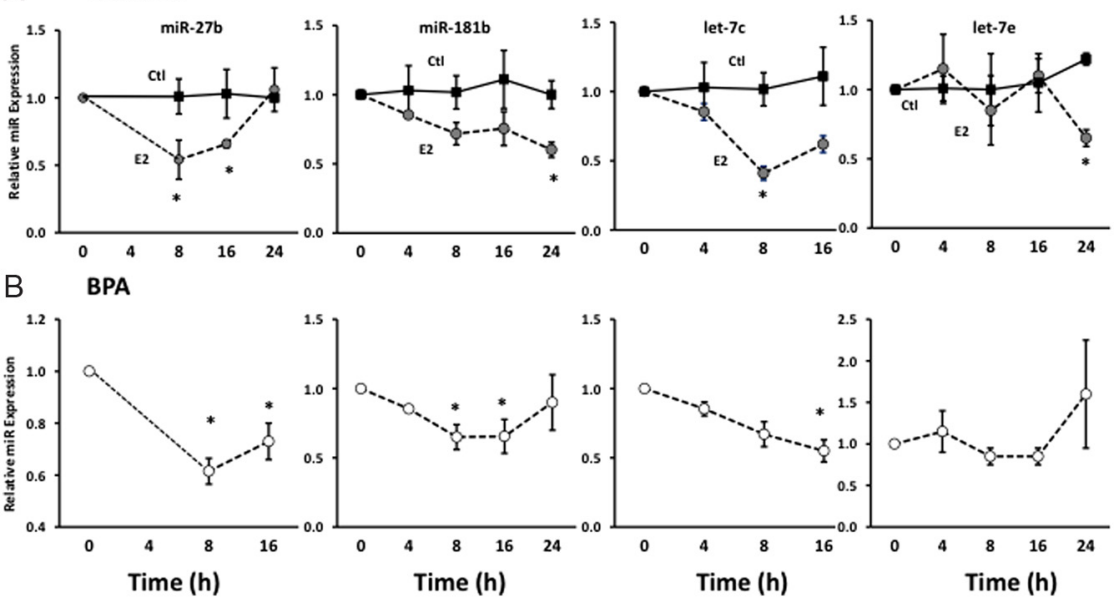

Figure 3 E2- and BPA-induced regulation of miR-27b, -181b, let-7c and let-7e. HESCs were treated with E2 (3 nM) (A) or BPA (B) as a function of time. RNA was isolated at baseline or various times after treatment (4-24 h). Panel A depicts treatment with vehicle (Ctl, black squares) or E2 (circles). Panel B represents data after treatment with BPA $(3 \mu \mathrm{M})$. Data represent mean \pm S.E.M. of representative experiments conducted in triplicate and repeated in six cell preps except let-7c, which was conducted in one cell prep. $* P<0.05$ compared with baseline, ANOVA with Dunnett's post hoc testing using time 0 as the control. 

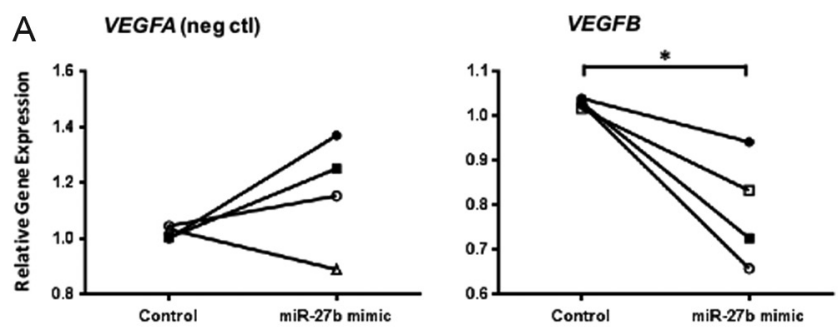

B VEGFB

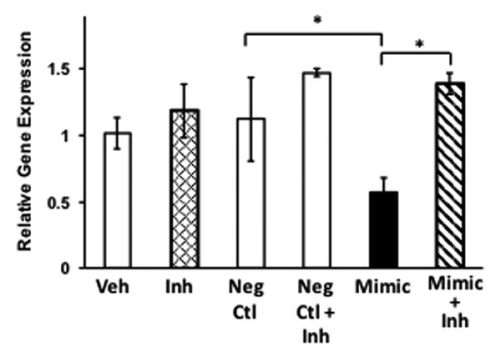

Figure $4 V E G F B$ is a target of miR-27b in human endometrial stromal cells. (A) HESCs were transfected with negative control or miR-27b mimic for $48 \mathrm{~h}$ in cell preps from four different patients. Gene expression of VEGFA (negative control), and VEGFB were quantified by qPCR. Each symbol represents mean values of triplicates from each cell prep. ${ }^{*} P<0.05$, paired $t$-test. (B) Cells were treated with vehicle, miR-27b inhibitor, negative control, negative control + inhibitor, miR-27b mimic, or miR-27b mimic + inhibitor for $48 \mathrm{~h}$. Thereafter, relative mRNA levels of VEGFB were determined. $* P<0.05$, ANOVA.

CAMP and medroxyprogesterone acetate for 8 days. Decidualization was assessed by increased expression of PRL and IGFBP1 mRNA and morphological change in the cells (not shown). Interestingly, miR-27b was downregulated with decidualization (Fig. 7) in seven different cell preps.

\section{Discussion}

Several investigations have profiled miRNA expression in secretory and proliferative endometrium (Kuokkanen et al. 2010, Wessels et al. 2013, Dior et al. 2014) and differences in miRNA expression in spontaneous decidualized endometrium and early pregnancy decidua (Wang et al. 2016). In some studies, the endometrium was considered as a whole tissue (Ohlsson Teague et al. 2009), whereas in others, endometrial epithelial cells were targeted. It is thereby difficult to ascertain the cell type of miR expression and bona fide targets within the cell type of origin or adjacent cells. Here, we hypothesized that various miRNAs may play a role in estrogen- and progesterone-induced development of the endometrial stroma. Further, we speculated that the hormone disruptor BPA may alter endometrial miR gene expression.

Microarray analysis of HESCs treated with E2 and/or P4 supports the differential expression of many miRs in human endometrial stromal cells with exposure to E2. Because the microarray only examined expression of
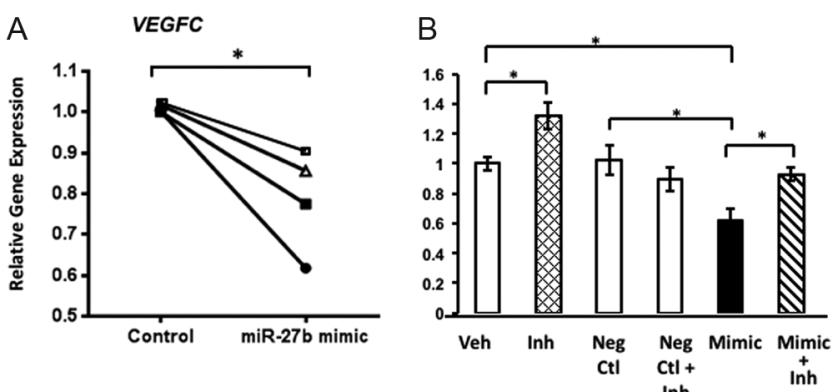

Figure 5 VEGFC is a target of miR-27b in human endometrial stromal cells. (A) HESCs were transfected with negative control or miR-27b mimic for $48 \mathrm{~h}$ in cell preps from four different patients. Gene expression of VEGFC was quantified by qPCR. Each symbol represents mean values of triplicates from each cell prep. ${ }^{*} P<0.05$, paired $t$-test. (B) Cells were treated with vehicle, miR-27b inhibitor, negative control, negative control + inhibitor, miR-27b mimic, or miR$27 \mathrm{~b}$ mimic + inhibitor for $48 \mathrm{~h}$. Thereafter, relative mRNA levels of VEGFC were determined. ${ }^{*} P<0.05$, ANOVA.

miRs at a single point in time and in a single patient, it served as a springboard to investigate temporal relationships between estradiol, miR expression and regulation in primary cell cultures. We show for the first time that miR-27b is downregulated by E2 and BPA in endometrial stromal cells, and we identified miR-27b targets in these cells. The results are in agreement with Wang et al. in which E2 downregulated miR-27b in a leukemia cell line (Wang et al. 2014) and with Ye et al. in which VEGFC was shown to be a validated target of miR27b in 293T and colorectal cancer cells (Ye et al. 2013).

\section{Physiological relevance of miR-27b}

miR-27b is often considered a tumor suppressor. It has been shown to be downregulated in several cancers, including colorectal cancer and neuroblastoma (Lee et al. 2012, Ye et al. 2013). It has been suggested that miR-27b may inhibit tumor cell proliferation, migration and invasion. Our results indicate that one potential mechanism by which miR-27b may regulate these processes is through regulation of VEGFC (Ye et al. 2013). As miR-27b is lost in cancer cells, VEGFC
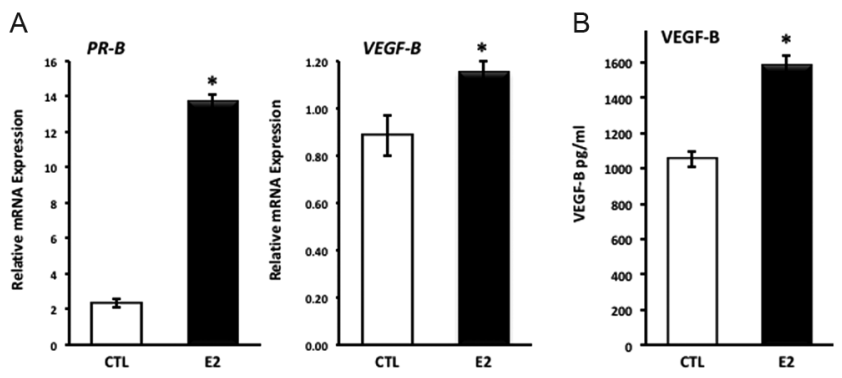

Figure 6 E2 regulates VEGF-B mRNA and protein. HESCs were treated with vehicle (CTL) or E2 (3.6nM) for 4 days. (A) To confirm estrogen responsiveness, $P R-B$ and $V E G F-B$ mRNA was quantified. VEGF-B protein was quantified in media. ${ }^{*} P<0.05$, Students $t$-test. 


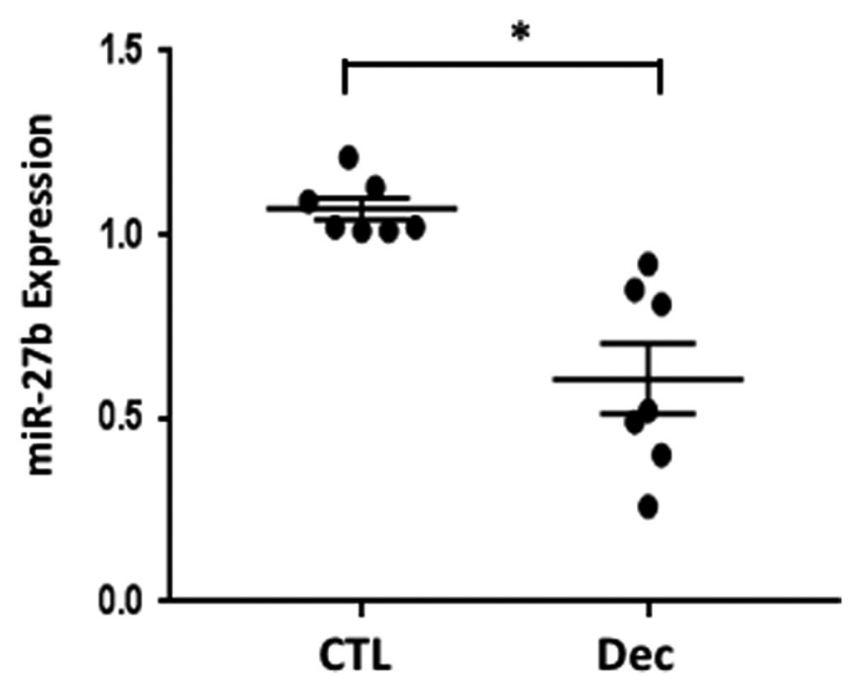

Figure 7 In vitro decidualization downregulates miR-27b. HESCs were decidualized in vitro for 8 days. miR-27b expression was quantified by qPCR. Data represent mean values of seven cell preps conducted in triplicate. ${ }^{*} P<0.05$, paired $t$-test.

expression increases, resulting in increased metastatic potential. VEGFC induces new blood vessel formation and endothelial cell proliferation and migration (Van Trappen \& Pepper 2005). Further, our results support a role for miR-27b in regulation of VEGF-B.

Invasion of the blastocyst into the endometrium during pregnancy implantation has many similarities with invasion of cancer cells. We show that miR-27b is decreased during decidualization. It is known that VEGF production increases during decidualization and embryo implantation. Our results are compatible, therefore, with the possible involvement of miR-27b in regulating VEGFB and C and thereby new blood vessel formation and endothelial cell proliferation and migration during decidualization. Furthermore, VEGFs are E2 responsive and E2 is required for the initial increase of VEGFs that occur in the mid- to late-proliferative phase of the menstrual cycle (Nayak \& Brenner 2002).

\section{BPA regulates $\mathrm{miR}-27 \mathrm{~b}$}

BPA exposure is associated with increased vascular tube formation and branching points, as well as increased VEGFD mRNA and protein in human endometrial endothelial cells that also express ER $\beta$ (Helmestam et al. 2014). These findings suggest that BPA may alter normal vasculogenesis in the endometrium and impact its development and possibly embryo implantation. BPA also impairs placentation (Lan et al. 2017). Recently, BPA has been shown to alter endometrial stromal cell decidualization in vitro. Olson et al. used physiologic and supraphysiologic concentrations of BPA during in vitro decidualization for 8 days (Olson et al. 2017). They found that $10 \mu \mathrm{g} / \mathrm{mL}$ and $20 \mu \mathrm{g} / \mathrm{mL}$ were required to prevent decidualization, proliferation and alter $E R \alpha$,
$P G R$ and cell cycle gene expression. The authors note that although these concentrations are greater than typical human exposure, the data support the impact of BPA on reproductive tissues.

Our data further support that BPA has a negative impact on the endometrium. Our initial experiments do not suggest an additive effect of BPA and E2; however, the impact in vivo is unclear. Nonetheless, exposure to BPA during the early proliferative phase when E2 levels are low may alter the timing of downregulation of miR-27b, and therefore, increase expression of its targets, $V E G F B$ and $V E G F C$, prematurely leading to dysregulation of angiogenesis. The progressive and orderly development of the endometrium is well established and disruption in the process by BPA may contribute to the development of gynecologic disorders involving increased angiogenesis and VEGF gene expression in conditions such as endometriosis (Oosterlynck et al. 1993, McLaren et al. 1996), abnormal decidualization or implantation failure.

\section{Summary}

The strengths of this study include the use of multiple cell preps of endometrial stromal cells in primary culture to ensure as much conformity as possible, and time course investigations demonstrating that single time point microarrays may be misleading. Further, the results were validated using stably expressed microRNAs as reference genes. To narrow the scope of the investigation, we focused on E2- and BPA-induced regulation of miRs. One caveat is that miRs have the ability to affect targets at the mRNA or the protein level. Here, we show that E2 induced downregulation of miR-27b and also led to increased secretion of the miR-27b target, VEGF-B. Other translational targets were not investigated. Further, we did not conduct a comprehensive evaluation of these miRs during combination treatment $(\mathrm{BPA}+\mathrm{E} 2)$ or endometrial decidualization, studies which are now ongoing. Nevertheless, our data indicate that BPA and E2 affect miR expression in endometrial stromal cells and may impact targets important for endometrial development. Identification of $V E G F B$ and $V E G F C$ as miR-27b target genes suggests that BPA and E2 alter genes important for vascularization and angiogenesis of the endometrium during the menstrual cycle, decidualization or ectopic implantation.

\section{Supplementary data}

This is linked to the online version of the paper at https://doi.org/10.1530/REP-18-0041.

\section{Declaration of interest}

The authors declare that there is no conflict of interest that could be perceived as prejudicing the impartiality of the research reported. 


\section{Funding}

This work was supported by the Human Biological Fluids Tissue Acquisition Laboratory (NIH P01HD087150) for endometrial specimens. The research was supported by grant K12 HD000849 (P T J), awarded to the Reproductive Scientist Development Program by the Eunice Kennedy Shriver National Institute of Child Health and Human Development and by the Burroughs Wellcome Fund, as part of the Reproductive Scientist Development Program.

\section{Acknowledgements}

The authors thank the physicians and staff of Parkland Hospital and Sylvia Wright for tissue procurement.

\section{References}

Aghajanova L \& Giudice LC 2011 Effect of bisphenol A on human endometrial stromal fibroblasts in vitro. Reproductive Biomedicine Online 22 249-256. (https://doi.org/10.1016/j.rbmo.2010.12.007)

Barbonetti A, Castellini C, Di Giammarco N, Santilli G, Francavilla S \& Francavilla F 2016 In vitro exposure of human spermatozoa to bisphenol A induces pro-oxidative/apoptotic mitochondrial dysfunction. Reproductive Toxicology 66 61-67. (https://doi.org/10.1016/j. reprotox.2016.09.014)

Bechi N, letta F, Romagnoli R, Jantra S, Cencini M, Galassi G, Serchi T, Corsi I, Focardi S \& Paulesu L 2010 Environmental levels of paranonylphenol are able to affect cytokine secretion in human placenta. Environmental Health Perspectives 118 427-431. (https://doi. org/10.1289/ehp.0900882)

Berger RG, Hancock T \& deCatanzaro D 2007 Influence of oral and subcutaneous bisphenol-A on intrauterine implantation of fertilized ova in inseminated female mice. Reproductive Toxicology 23 138-144. (https://doi.org/10.1016/j.reprotox.2006.09.005)

Calafat AM, Ye X, Wong LY, Reidy JA \& Needham LL 2008 Exposure of the U.S. population to bisphenol A and 4-tertiary-octylphenol: 2003-2004. Environmental Health Perspectives 116 39-44. (https://doi.org/10.1289/ ehp.10753)

Casey ML, Smith JW, Nagai K, Hersh LB \& MacDonald PC 1991 Progesterone-regulated cyclic modulation of membrane metalloendopeptidase (enkephalinase) in human endometrium. Journal of Biological Chemistry $26623041-23047$.

Chen Z-J, Yang X-L, Liu H, Wei W, Zhang K-S, Huang H-B, Giesy JP, Liu HL, Du J \& Wang H-S 2015 Bisphenol A modulates colorectal cancer protein profile and promotes the metastasis via induction of epithelial to mesenchymal transitions. Archives of Toxicology 89 1371-1381. (https:// doi.org/10.1007/s00204-014-1301-z)

Chen H, Fan Y, Xu W, Chen J, Meng Y, Fang D \& Wang J 2017a Exploration of miR-1202 and miR-196a in human endometrial cancer based on high throughout gene screening analysis. Oncology Reports 37 3493-3501. (https://doi.org/10.3892/or.2017.5596)

Chen C, Ponnusamy M, Liu C, Gao J, Wang K \& Li P 2017b MicroRNA as a therapeutic target in cardiac remodeling. BioMed Research International 2017 1-25. (https://doi.org/10.1155/2017/1278436)

Dairkee SH, Luciani-Torres MG, Moore DH \& Goodson WH 2013 Bisphenol-A-induced inactivation of the p53 axis underlying deregulation of proliferation kinetics, and cell death in non-malignant human breast epithelial cells. Carcinogenesis 34 703-712. (https://doi. org/10.1093/carcin/bgs379)

Diamanti-Kandarakis E, Bourguignon JP, Giudice LC, Hauser R, Prins GS, Soto AM, Zoeller RT and Gore AC 2009 Endocrine-disrupting chemicals: an Endocrine Society scientific statement. Endocrine Reviews $\mathbf{3 0}$ 293-342. (https://doi.org/10.1210/er.2009-0002)

Dior UP, Kogan L, Chill HH, Eizenberg N, Simon A \& Revel A 2014 Emerging roles of microRNA in the embryo-endometrium cross talk. Seminars in Reproductive Medicine 32 402-409. (https://doi. org/10.1055/s-0034-1376359)
Dong Y, Araki M, Hirane M, Tanabe E, Fukushima N \& Tsujiuchi T 2014 Effects of bisphenol A and 4-nonylphenol on cellular responses through the different induction of LPA receptors in liver epithelial WB-F344 cells. Journal of Receptor and Signal Transduction Research 34 201-204. (https://doi.org/10.3109/10799893.2013.876040)

Ehrlich S, Williams PL, Missmer SA, Flaws JA, Berry KF, Calafat AM, Ye X, Petrozza JC, Wright D \& Hauser R 2012 Urinary bisphenol A concentrations and implantation failure among women undergoing in vitro fertilization. Environmental Health Perspectives 120 978-983. (https://doi.org/10.1289/ehp.1104307)

Forte M, Mita L, Cobellis L, Merafina V, Specchio R, Rossi S, Mita DG, Mosca L, Castaldi MA, De Falco M et al. 2016 Triclosan and bisphenol A affect decidualization of human endometrial stromal cells. Molecular and Cellular Endocrinology 422 74-83. (https://doi.org/10.1016/j. mce.2015.11.017)

Lan X, Fu L-J, Zhang J, Liu X-Q, Zhang H-J, Zhang X, Ma M-F, Chen X-M, He J-L, Li L-B et al. 2017 Bisphenol A exposure promotes HTR-8/SVneo cell migration and impairs mouse placentation involving upregulation of integrin- $\beta 1$ and MMP-9 and stimulation of MAPK and PI3K signaling pathways Lan. Oncotarget 8 X 51507-51521. (https://doi.org/10.18632/ oncotarget.17882)

Ganesan S \& Keating AF 2016 Bisphenol A-induced ovotoxicity involves DNA damage induction to which the ovary mounts a protective response indicated by increased expression of proteins involved in DNA repair and xenobiotic biotransformation. Toxicological Sciences 152 169-180. (https://doi.org/10.1093/toxsci/kfw076)

Gore AC 2007 Endocrine-Disrupting Chemicals : From Basic Research to Clinical Practice. Totowa, NJ: Humana Press.

Helmestam M, Davey E, Stavreus-Evers A \& Olovsson M 2014 Bisphenol A affects human endometrial endothelial cell angiogenic activity in vitro. Reproductive Toxicology 46 69-76. (https://doi.org/10.1016/j. reprotox.2014.03.002)

Hormann AM, vom Saal FS, Nagel SC, Stahlhut RW, Moyer CL, Ellersieck MR, Welshons WV, Toutain P-L \& Taylor Ja 2014 Holding thermal receipt paper and eating food after using hand sanitizer results in high serum bioactive and urine total levels of bisphenol A (BPA). PLOS ONE 9. (https://doi.org/10.1371/journal.pone.0110509)

Hwang JK, Min KH, Choi KH, Hwang YC, Jeong I-K, Ahn KJ, Chung HY \& Chang JS 2013 Bisphenol A reduces differentiation and stimulates apoptosis of osteoclasts and osteoblasts. Life Sciences 93 367-372. (https://doi.org/10.1016/j.lfs.2013.07.020)

Itoh K, Yaoi T \& Fushiki S 2012a Bisphenol A, an endocrine-disrupting chemical, and brain development. Neuropathology 32 447-457. (https:// doi.org/10.1111/j.1440-1789.2011.01287.x)

Itoh H, Kishore AH, Lindqvist A, Rogers DE \& Word RA 2012b Transforming growth factor $\beta 1$ (TGF $\beta 1$ ) and progesterone regulate matrix metalloproteinases (MMP) in human endometrial stromal cells. Journal of Clinical Endocrinology and Metabolism. (https://doi.org/10.1210/ jc.2011-3073)

Jimenez PT, Mainigi MA, Word RA, Kraus WL \& Mendelson CR 2016 miR200 regulates endometrial development during early pregnancy. Molecular Endocrinology 30 977-987. (https://doi.org/10.1210/me.2016-1050)

Kang T, Lu W, Xu W, Anderson L, Bacanamwo M, Thompson W, Chen YE \& Liu D 2013 MicroRNA-27 (miR-27) targets prohibitin and impairs adipocyte differentiation and mitochondrial function in human adiposederived stem cells. Journal of Biological Chemistry 288 34394-34402. (https://doi.org/10.1074/jbc.M113.514372)

Kettel LM, Roseff SJ, Bangah ML, Burger HG \& Yen SS 1991 Circulating levels of inhibin in pregnant women at term: simultaneous disappearance with oestradiol and progesterone after delivery. Clinical Endocrinology 34 19-23. (https://doi.org/10.1111/j.1365-2265.1991. tb01730.x)

Krishnan AV, Stathis P, Permuth SF, Tokes L \& Feldman D 1993 Bisphenol-A: an estrogenic substance is released from polycarbonate flasks during autoclaving. Endocrinology 132 2279-2286. (https://doi.org/10.1210/ endo.132.6.8504731)

Kuokkanen S, Chen B, Ojalvo L, Benard L, Santoro N \& Pollard JW 2010 Genomic profiling of microRNAs and messenger RNAs reveals hormonal regulation in microRNA expression in human Endometrium1. Biology of Reproduction 82 791-801. (https://doi.org/10.1095/biolreprod.109.081059)

Lee J-J, Drakaki A, Iliopoulos D \& Struhl K 2012 MiR-27b targets PPAR $\gamma$ to inhibit growth, tumor progression and the inflammatory response in 
neuroblastoma cells. Oncogene 31 3818-3825. (https://doi.org/10.1038/ onc.2011.543)

Lenton EA, Sulaiman R, Sobowale O \& Cooke ID 1982 The human menstrual cycle: plasma concentrations of prolactin, $\mathrm{LH}, \mathrm{FSH}$, oestradiol and progesterone in conceiving and non-conceiving women. Journal of Reproduction and Fertility 65 131-139. (https://doi.org/10.1530/ jrf.0.0650131)

Liao C, Liu F \& Kannan K 2012 Bisphenol S, a new bisphenol analogue, in paper products and currency bills and its association with bisphenol A residues. Environmental Science and Technology 46 6515-6522. (https://doi.org/10.1021/es300876n)

Logan PC, Yango P \& Tran ND 2017 Endometrial stromal and epithelial cells exhibit unique aberrant molecular defects in patients with endometriosis. Reproductive Sciences 25 140-159. (https://doi. org/10.1177/19337191177049059)

Machtinger R \& Orvieto R 2014 Bisphenol A, oocyte maturation, implantation, and IVF outcome: review of animal and human data. Reproductive Biomedicine Online 29 404-410. (https://doi. org/10.1016/j.rbmo.2014.06.013)

Makker A \& Goel MM 2013 Uterine leiomyomas: effects on architectural, cellular, and molecular determinants of endometrial receptivity. Reproductive Sciences 20 631-638. (https://doi. org/10.1177/1933719112459221)

Mansur A, Israel A, Combelles CMH, Adir M, Racowsky C, Hauser R, Baccarelli AA \& Machtinger R 2017 Bisphenol-A exposure and gene expression in human luteinized membrana granulosa cells in vitro. Human Reproduction 32 409-417. (https://doi.org/10.1093/humrep/dew316)

Marsh EE, Steinberg ML, Parker JB, Wu J, Chakravarti D \& Bulun SE 2016 Decreased expression of microRNA-29 family in leiomyoma contributes to increased major fibrillar collagen production. Fertility and Sterility 106 766-772. (https://doi.org/10.1016/j.fertnstert.2016.05.001)

McLaren J, Prentice A, Charnock-Jones DS \& Smith SK 1996 Vascular endothelial growth factor (VEGF) concentrations are elevated in peritoneal fluid of women with endometriosis. Human Reproduction 11 220-223. (https://doi.org/10.1093/oxfordjournals.humrep.a019023)

Meeker JD, Ehrlich S, Toth TL, Wright DL, Calafat AM, Trisini AT, Ye X \& Hauser R 2010 Semen quality and sperm DNA damage in relation to urinary bisphenol A among men from an infertility clinic. Reproductive Toxicology 30 532-539. (https://doi.org/10.1016/j.reprotox.2010.07.005)

Nakano K, Nishio M, Kobayashi N, Hiradate Y, Hoshino Y, Sato E \& Tanemura K 2016 Comparison of the effects of BPA and BPAF on oocyte spindle assembly and polar body release in mice. Zygote 24 172-180. (https://doi.org/10.1017/S0967199415000027)

Nayak NR \& Brenner RM 2002 Vascular proliferation and vascular endothelial growth factor expression in the rhesus macaque endometrium. Journal of Clinical Endocrinology and Metabolism $\mathbf{8 7}$ 1845-1855. (https://doi.org/10.1210/jcem.87.4.8413)

Nothnick WB, Falcone T, Joshi N, Fazleabas AT \& Graham A 2016 Serum miR-451a levels are significantly elevated in women with endometriosis and recapitulated in baboons (Papio anubis) with experimentallyinduced disease. Reproductive Sciences 24 1195-1202. (https://doi. org/10.1177/1933719116681519)

Ohlsson Teague EMC, Van der Hoek KH, Van der Hoek MB, Perry N, Wagaarachchi P, Robertson SA, Print CG \& Hull LM 2009 MicroRNAregulated pathways associated with endometriosis. Molecular Endocrinology 23 265-275. (https://doi.org/10.1210/me.2008-0387)

Olson MR, Su R, Flaws JA \& Fazleabas AT 2017 Bisphenol A impairs decidualization of human uterine stromal fibroblasts. Reproductive Toxicology 73 339-344. (https://doi.org/10.1016/j.reprotox.2017.07.008)

Oosterlynck DJ, Meuleman C, Sobis H, Vandeputte M \& Koninckx PR 1993 Angiogenic activity of peritoneal fluid from women with endometriosis. Fertility and Sterility 59 778-782. (https://doi.org/10.1016/S00150282(16)55859-2)

Peretz J, Vrooman L, Ricke Wa, Hunt Pa, Ehrlich S, Hauser R, Padmanabhan V, Taylor HS, Swan SH, Vandevoort Ca et al. 2014 Bisphenol A and reproductive health: update of experimental and human evidence, 2007-2013. Environmental Health Perspectives 122 775-786. (https://doi.org/10.1289/ehp.1307728)

Provvisiero D, Pivonello C, Muscogiuri G, Negri M, de Angelis C, Simeoli C, Pivonello R \& Colao A 2016 Influence of bisphenol A on type 2 diabetes mellitus. International Journal of Environmental Research and Public Health 13 989. (https://doi.org/10.3390/ijerph13100989)
Qiong Z, Jie H, Yonggang W, Bin X, Jing Z \& Yanping L 2017 Clinical validation of pinopode as a marker of endometrial receptivity: a randomized controlled trial. Fertility and Sterility 108 513-517.e2. (https://doi.org/10.1016/j.fertnstert.2017.07.006)

Rancière F, Lyons JG, Loh VHY, Botton J, Galloway T, Wang T, Shaw JE \& Magliano DJ 2015 Bisphenol A and the risk of cardiometabolic disorders: a systematic review with meta-analysis of the epidemiological evidence. Environmental Health 14 46. (https://doi.org/10.1186/s12940015-0036-5)

Rekker K, Saare M, Roost AM, Salumets A \& Peters M 2013 Circulating microRNA profile throughout the menstrual cycle. PLOS ONE 8. (https:// doi.org/10.1371/journal.pone.0081166)

Renthal NE, Chen CC, Williams KC, Gerard RD, Prange-Kiel J \& Mendelson CR 2010 miR-200 family and targets, ZEB1 and ZEB2, modulate uterine quiescence and contractility during pregnancy and labor. PNAS 107 20828-20833. (https://doi.org/10.1073/ pnas.1008301107)

Shen Y, Li Y, Ye F, Wang F, Wan X, Lu W \& Xie X 2011 Identification of $\mathrm{miR}-23 \mathrm{a}$ as a novel microRNA normalizer for relative quantification in human uterine cervical tissues. Experimental and Molecular Medicine 43 358-366. (https://doi.org/10.3858/emm.2011.43.6.039)

Snowdon J, Zhang X, Childs T, Tron VA \& Feilotter H 2011 The MicroRNA-200 family is upregulated in endometrial carcinoma. PLOS ONE 6. (https://doi.org/10.1371/journal.pone.0022828)

Souter I, Smith KW, Dimitriadis I, Ehrlich S, Williams PL, Calafat AM \& Hauser R 2013 The association of bisphenol-A urinary concentrations with antral follicle counts and other measures of ovarian reserve in women undergoing infertility treatments. Reproductive Toxicology $\mathbf{4 2}$ 224-231. (https://doi.org/10.1016/j.reprotox.2013.09.008)

Sugiura-Ogasawara M, Ozaki Y, Sonta SI, Makino T \& Suzumori K 2005 Exposure to bisphenol $\mathrm{A}$ is associated with recurrent miscarriage. Human Reproduction 20 2325-2329. (https://doi.org/10.1093/humrep/deh888)

Van Trappen PO \& Pepper MS 2005 Lymphangiogenesis in human gynaecological cancers. Angiogenesis 8 137-145. (https://doi. org/10.1007/s10456-005-9008-7)

Wang B, Li D, Kovalchuk A, Litvinov D \& Kovalchuk O 2014 lonizing radiation-inducible miR-27b suppresses leukemia proliferation via targeting cyclin A2. International Journal of Radiation Oncology, Biology, Physics 90 53-62. (https://doi.org/10.1016/j.ijrobp.2014.04.055)

Wang Y, Lv Y, Gao S, Zhang Y, Sun J, Gong C, Chen X \& Li G 2016 MicroRNA profiles in spontaneous decidualized menstrual endometrium and early pregnancy decidua with successfully implanted embryos. PLoS ONE 11. (https://doi.org/10.1371/journal.pone.0143116)

Wessels JM, Edwards AK, Khalaj K, Kridli RT, Bidarimath M \& Tayade C 2013 The microRNAome of pregnancy: deciphering miRNA networks at the maternal-fetal interface. PLOS ONE 8. (https://doi.org/10.1371/ journal.pone.0072264)

Wilczynski M, Danielska J, Dzieniecka M, Szymanska B, Wojciechowski M \& Malinowski A 2016 Prognostic and clinical significance of miRNA-205 in endometrioid endometrial cancer. PLOS ONE 11. (https://doi. org/10.1371/journal.pone.0164687)

Ye J, Wu X, Wu D, Wu P, Ni C, Zhang Z, Chen Z, Qiu F, Xu J \& Huang J 2013 miRNA-27b Targets vascular endothelial growth factor $C$ to inhibit tumor progression and angiogenesis in colorectal cancer. PLOS ONE 8 e60687. (https://doi.org/10.1371/journal.pone.0060687)

Zhang T, Huang C, Du Y, Lian R, Mo M, Zeng Y \& Mor G 2017 Successful treatment with intrauterine delivery of dexamethasone for repeated implantation failure. American Journal of Reproductive Immunology e12766. (https://doi.org/10.1111/aji.12766)

Ziv-Gal A \& Flaws JA 2016 Evidence for bisphenol A-induced female infertility: a review (2007-2016). Fertility and Sterility 106 827-856. (https://doi.org/10.1016/j.fertnstert.2016.06.027)

Received 20 January 2018

First decision 21 February 2018

Revised manuscript received 20 August 2018

Accepted 28 September 2018 